\title{
A HISTORICAL ACCOUNT ON THE USE OF KEROSENE TO TRAP THE MEDITERRANEAN FRUIT FLY (CERATITIS CAPITATA WIED.)
}

By Henry H. P. Severin, Ph.D., Honorary Fellow, University of Wisconsin, and Harry C. Severin, M. A., Professor of Entomology, South Dakota State College of Agriculture and Mechanic Arts

The economic entomologist, owing to his vast field is compelled at times to recommend measures for the control of insects that are troublesome in his territory, even though he himself or his staff have not put these measures to a practical test. In not exactly rare instances, recommendations for the control of pests creep into text-books, station bulletins and entomological journals, and these measures even if followed out to the letter will be practically worthless in every locality where they are adopted. As an excellent illustration of a worthless recommendation for the control of a pest is the use of kerosene to trap the Mediterranean fruit fly.

In this paper we shall first place before the reader the results of our experiments in attempting to control the Mediterranean fruit fly by means of kerosene traps and then we shall follow this with a historical account of this method of control as practiced or recommended in various parts of the world.

The attempt on our part to control the Mediterranean fruit fly by the

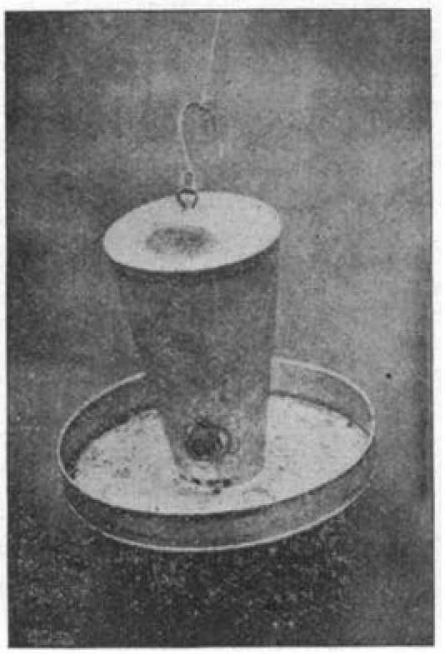

Fig. 5. Self-feeding keros'ne fountain for the capture of the Mediterranean fruit fly in Western Australia.

use of kerosene traps wired to fruit trees was a complete failure. In one experiment 10 traps were wired in 10 fruit-bearing citrus trees located in different parts of an orchard and in five weeks, 10,239 fruit flies were captured; of this entire number, only 36 were females, the remainder being males. At the end of the five weeks nearly every ripe orange in this orchard had been "stung" by the pest. Trapping the Mediterranean fruit fly with kerosene was carried on for a period of eight months in the Hawaiian Islands in connection with other experiments and the results show that of every 1,000 fruit flies captured only three on an average were females, the remainder being males. After taking Weinland into the field and showing him the methods 
which we employed in trapping the pest with kerosene, similar experiments were performed by this entomologist. Weinland (1912, p. 264) found that "the proportion of females to males caught is about 1 to 200." Howlett (1912, p. 413) in experimenting on the effect of oil of citronella on the Trypetid, Dacus zonatus Saund., found that of 18,000 specimens captured with this oil, "not more than 50 females were seen, or 0.3 per cent" of the total number of insects caught.

One would naturally suppose that the destruction of thousands of males in an orchard would soon lead to unfertilized females, for the opportunity that a female would have of copulating under such conditions would be greatly reduced. But whether or not a male will copulate more than once has not as yet been proven, nor has it been shown that the eggs of the fruit fly will or will not develop without fertilization. Furthermore, it is not to be inferred that all of the males in the immediate neighborhood of a kerosene trap are caught in a few days, for dozens of them may be captured week after week by sweeping among the leaves of the trees with an insect net. Dewar (1908, p. 3) frequently saw Mediterranean fruit flies around the tin containing the kerosene. Some of the flies would rest on the edge of the tin and later fly away without having touched the oil. "It seems clear that the oil caught only a certain percentage of the flies and that the others continued about the tree as usual." This is an observation which we can confirm.

Compere, chief quarantine inspector at San Francisco, has kindly given us the following account of the discovery that the Mediterranean fruit fly is attracted to kerosene. At Guilford, Australia, a farmer's wife had prepared some jam and because the ants were numerous around the house, she set the dish containing the jam on a hitching post to cool. To prevent the ants from crawling up to the jam, she daubed kerosene on the post. Towards evening, the daughter, a girl of eight years, noticed that the Mediterranean fruit flies were swarming around the post and she immediately called her mother's attention to this fact. It was thought at first that the fruit flies had been attracted to the jam, but after the father's attention had been called to the matter he investigated and found that the kerosene had attracted the pest. According to the Sydney Morning Herald (1907, p. 645) Devenish who made this discovery, caught 2,000 Mediterranean fruit flies in vessels containing kerosene, in the course of a week in his orchard. According to this account the credit of the discovery that kerosene attracts the Mediterranean fruit fly belongs in part at least to this youthful observer of nature.

In the further history of the use of kerosene to control the Mediterranean fruit fly in Australia, it will be seen that this new discovery 
was not put under a severe experimental test by the entomologists before recommending and even forcing the people to use this method.

In Western Australia, Jefferson (1907, p. 162) was the first to report that "some good results have recently been obtained by using kerosene to attract and kill the flies."

During the same year, Compere and Newman (1907, p. 245) both of Western Australia, carried on an experiment with kerosene to trap the Mediterranean fruit fly. A vessel containing kerosene was placed in the forks of a tree and " 18 hours later Newman removed and counted! 124 fruit flies." No mention, however, was made of the percentage. of male and female specimens taken. "Female flies removed from the oil showed upon examination to be fertile, being yet full of eggs." It was probably this last statement that influenced some entomologists: to take it for granted that many female flies were attracted to the kerosene. This is shown through the interpretation of the above results by Quinn (1907, p. 12) of South Australia who writes as follows: "It is significant to note that many of these were females, containing large numbers of undeposited eggs, showing that the attractivenessof the kerosene took precedence over the instinct of egg deposition."

Hooper (1907, p. 696) also of Western Australia issued the following instructions in 1907, to all orchardists and those people who. happened to have one or two trees, and these directions were to beenforced that year: "All fallen fruit throughout the orchard must be gathered daily, and all maggoty fruit destroyed by burning or boiling. In addition to these precautions, throughout the summer shallow vessels: partly filled twice a week with kerosene must be placed one or more in each tree in the orchard, and shall be kept in or removed to such trees as an inspector may from time to time require."

In his "instructions to fruit growers" he also mentioned that "last season, in one orchard, 1,268 flies were destroyed by means of kerosene. in 24 hours," but the ratio of males to females captured was not given.

Hooper (1909, p. 271) writes as follows concerning the results obtained by enforcing the fruit fly regulations during the preceding year: "This year we are very free of the fruit fly compared with previous: years; this I put down principally to the compulsory use of kerosenelast autumn, and the clearing up and destruction of maggoty fruit."' In this same article he again recommends the use of kerosene to control the pest and enters into a discussion of the troubles experienced' by the inspectors in compelling the fruit growers to hang tins of kerosene in the trees. He also states that "the trifling cost of kerosene and the little amount of extra labor are covered over and over again by the value of the fruit saved." 
Newman (1910, p. 10) speaks very highly concerning the value of kerosene in controlling the pest: "The method of trapping the fly by the use of kerosene placed in bright, shallow, new tins, or better still in white saucers, has proved the most successful artificial method yet discovered and used in this state. . . . Large numbers of the flies have been captured by this simple means, and if consistently and universally used would cause a great reduction of the pest. Large numbers of the flies so caught have been examined and found to contain eggs." Newman now adds "large numbers" to his previous statement "female flies removed from the oil showed upon examination to be fertile, being yet full of eggs."

In New South Wales, Allen (1907, p. 546) experimented with kerosene to trap the Mediterranean fruit fly and says that the fly was "caught in quantities" but he fails to mention the number of males and females captured.

Gurney $(1908$, p. 581) and $(1910$, p. 425) also of New South Wales tried the kerosene method of controlling the Mediterranean fruit fly and writes, "As many as 200 adults have been captured in a couple of tins within three days." But like Allen he does not state the per cent of males and females captured.

A few South African entomologists also experimented with kerosene to trap the Mediterranean fruit fly and although some experimental work was carried on yet all of these entomologists overlooked the fact that the number of female flies captured in the oil form but a small per cent of the total number of flies caught.

Dewar (1908, p. 3) captured 444 fruit flies in 122 days in two tins containing kerosene, "one placed in, and the other under, a small citrus tree," but no mention was made of the ratio of males to females.

Mally (1908, pp. 3-5) tested the fondness of the fruit flies in captivity for kerosene and certain sweets. He liberated over 1,000 fruit flies in a cage containing two dishes of kerosene and "after six hours only 37 flies had been caught" but no mention was made of the number of males and females captured.

Lounsbury $(1908$, p. 6$)$ kept a record of the number of fruit flies that he captured in kerosene and in two of the catches he stated the number of males and females removed from the trap. "On January 19 the first fruit fly, a male, was found in the oil; and in the week following three more were taken. Then from January 26 to February 6 , five were taken. After that the catch became much better. Between February 6 and 11, 10 females and 12 males became victims. For the next 10 days the total was 19 , and for the next week, 15 ; and from then, February 28 to March 17 , the total was $30 . "$ 
Ehrhorn (1912, p. 4), superintendent of entomology in the Hawaiian Islands, writes as follows concerning the number of male and female Mediterranean fruit flies captured in kerosene traps. "Among the various experiments tried against the fruit fly, the use of kerosene traps has shown that enormous quantities of male flies can be trapped by this method, but so far very few females have been captured." The results of our investigations with the use of kerosene to trap the Mediterranean fruit fly were read in Honolulu before the Agricultural Seminar on November 9, 1911, and January 11, 1912, at which this entomologist was present and yet Ehrhorn has published this result as well as other observations which we announced at these scientific meetings without due credit being given to our labors.

\section{BIBLIOGRAPHY}

Allen, W. J., 1907. Orchard Notes. Agric. Gaz. N. S. W., XVIII, pp. 546-551. Compere, G., 1907. Kerosene Remedy and the Fruit Fly (Ceratitis capitata). Jour. Agric. Western Australia, XV, pp. 244-5.

Dewar, W. R., 1908. The Fruit Fly. Paraffin Remedy versus Poisoned Bait. Rept. Agric. Jour. Cape of Good Hope, May, No. 18, pp. 1-8.

Ehrhorn, E. M., 1912. The Mediterranean Fruit Fly (Ceratitis capitata Wied.) Bd. Agric. Forestry, Cir. No. 3, pp. 1-7.

Fulder, C., 1907. Paraffin and the Fruit Fly. Agric. Jour. Natal., X, pp. 645-6.

Gurney, W. B., 1908. Gosford-Narara Fruit Fly and Codling Moth Control Experiment. Agric. Gaz. N. S. W., XIX, pp. 581-4.

- 1910. Fruit Flies and other Insects Attacking Cultivated and Wild Fruits in New South Wales. Ibid., XXI, pp. 423-433.

Hoopen, T., 1907. Fruit Fly. Instructions to Fruit Growers. Jour. Agric. Western Australia, XV, pp. 696-7.

- 1909. Trapping Fruit Flies. Ibid., XVIII, p. 271.

Howletr, F. M, 1912. The Effect of Oil of Citronella on two Species of Dacus. Trans. Ent. Soc. London, pp. 412-8.

Jefferson, J. S., 1907. Fruit Fly. Jour. Agric. Western Australia, XV, pp. 160-6.

LodssbuRx, C. P., 1908. Supplementary Note by Government Entomologist. Rept. Agric. Jour. Cape of Good Hope, May, No. 18, pp. 6-8.

Mally, C. W., 1908. The Fruit Fly. Paraffin Remedy versus Poisoned Bait. Ibid., pp. I-5.

Newman, L. J., 1910. Fruit Fly. Dept. Agric. Indus. Western Australia, Bull. No. 38, pp. 1-11.

Quins, G., 1907. The Fruit-maggot-fly Pests. Dept. Agric. Intell. South Australia, Bull. No. 25, pp. 1-12.

Weinland, H. A., 1912. The Mediterranean Fruit Fly in Hawaii. Cal. State Comm. Hort. Mon. Bull. No. 7, I, pp. 261-270. 